\title{
Pola Fraktal sebagai Pemberi Bentuk Arsitektur Apartemen yang Menenangkan
}

\author{
Sadida Aghnia dan I Gusti Ngurah Antaryama \\ Departemen Arsitektur, Fakultas Teknik Sipil dan Perencanaan, Institut Teknologi Sepuluh Nopember (ITS) \\ e-mail: antaryama001@gmail.com
}

\begin{abstract}
Abstrak-Pertumbuhan penduduk secara terus menerus di kawasan perkotaan, menyebakan berbagai dampak pada masyarakat kota salah satunya adalah tingkat stress yang meningkat. Untuk menjawab permasalahan tersebut, desain ini bertujuan untuk penyembuhan khususnya tingkat stress manusia dimana apartemen sebagai objek eksplorasi dalam desain secara tidak sadar. Karena banyaknya hal yang dipikirkan manusa perkotaan juga keterbatasan waktu membuat otak secara sadar tak ingin diberi ruang untuk bekerja lebih lagi. Fraktal dengan rentang dimensi 1.3-1.5 digunakan untuk mencapai tujuan tersebut dengan cara menerapkan pola tersebut pada ekplorasi bentuk dan tatanan. Eksplorasi tersebut dipengaruhi oleh penentuan posisi-posisi paling optimal dari parameter yang memiliki banyak irisan. Penerapan pola fraktal ini menghasilkan arsitektur apartemen yang terdiri dari dua tower yang membesar di sisi atas dan halaman ditengahnya, dimana memungkinkan manusia bisa berinteraksi dengan elemen arsitektur secara visual. Dengan adanya interaksi visual tersebut, manusia dapat merasa lebih tenang karena melihat sebuah pola yang konfigurasinya dapat menurunkan tingkat stress manusia.
\end{abstract}

Kata Kunci-Fraktal, Pengalaman Visual, Superposisi, Tingkat Stress.

\section{PENDAHULUAN}

$\mathrm{K}$ ENAIKAN jumlah penduduk yang sejajar dengan kebutuhan rumah tinggal selalu terjadi, terutama di lingkungan perkotaan. Data dari Badan Pusat Statistik Indonesia (Gambar 1) menunjukkan bahwa jumlah penduduk Indonesia terus meningkat dan diproyeksikan akan terus meningkat. Hal tersebut memberikan dampak bagi penghuni kota salah satunya psikologis, karena banyaknya elemen yang secara proporsi atau skala menekan manusia, pemandangan yang membosankan yang membuat penghuni berakhir pada kejenuhan.

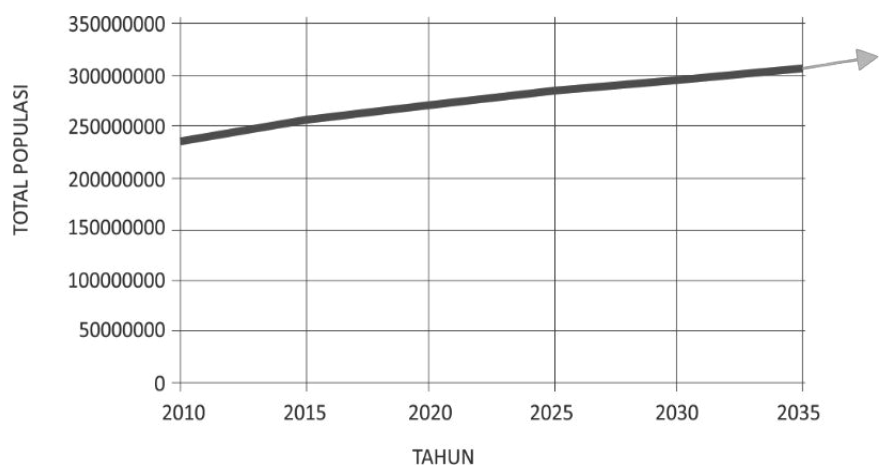

Gambar. 1. Diagram prediksi kenaikan jumlah penduduk yang diproyeksikan akan terus naik.
Kawasan industri menjadi salah satu konteks dalam pembicaraan ini. Tingkat stress bisa lebih terjadi di kawasan industri karena faktor lain selain faktor sosial, yaitu polusi dari tempat kerja itu sendiri yang dapat menimbulkan tekanan lingkungan yang dapat berdampak secara fisik maupun non fisik kepada manusia [1]. Oleh sebab itu, penulis memilih salah satu lahan di kawasan Rungkut Surabaya sebagai konteks lahan. Sebagai tanggapan terhadap kondisi tersebut, diusulkan sebuah desain apartemen yang dapat menurunkan tingkat stress manusia dan berlokasi di dekat jalan arteri yaitu Jl.Ir.H. Soekarno (Gambar 2).

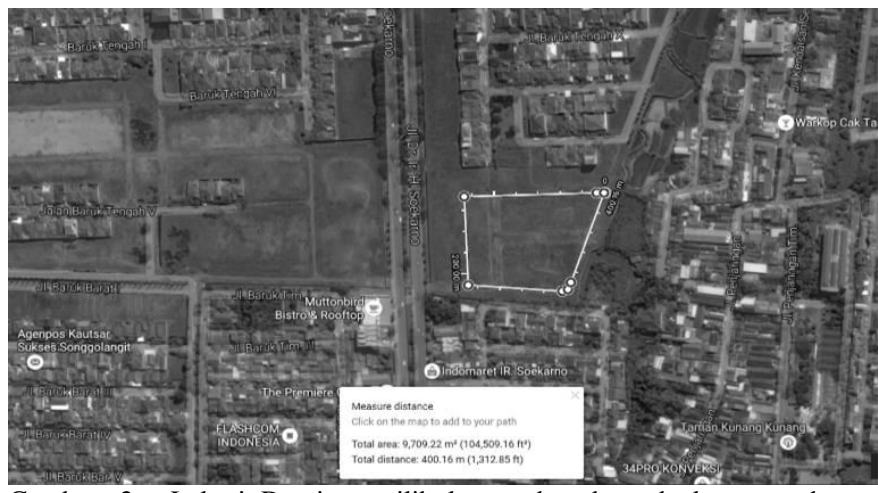

Gambar. 2. Lokasi Desain terpilih karena berada pada kawasan dengan tingkat stress yang tinggi. Lahan tersebut merupakan lahan yang potensial karena dekat dengan jalan arteri.

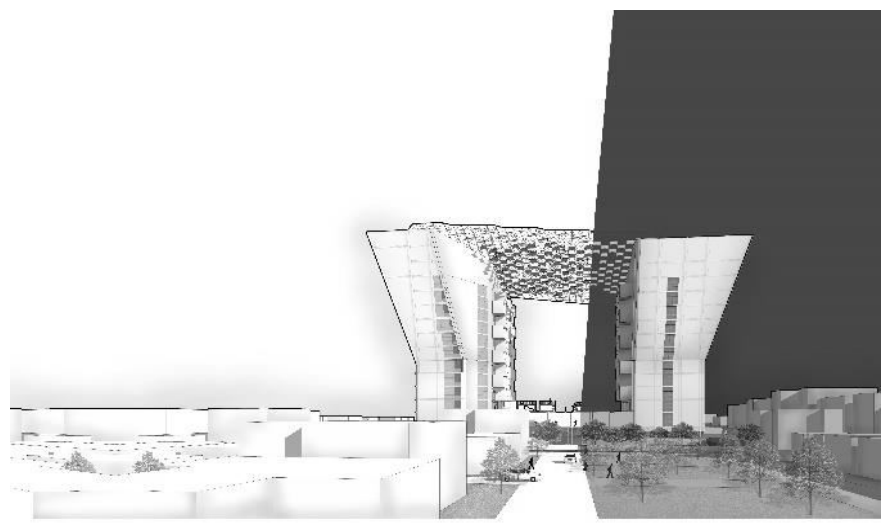

Gambar. 3. Perspektif dari sebelah barat ke utara lahan ini menunjukkan bahawa penerapan pola fraktal pada desain dapat dinikmati secar visual. Jika dari sudut pandang ini, sisi atap yang dapat dinikmati.

Desain apartemen pada objek kali ini menggunakan visualisasi pola fraktal yang dieksplorasi berdasarkan batasanbatasan tertentu (Gambar 3). Batasan-batasan tersebut ada dari lahan dan program yang dikehendaki. Eksplorasi pola fraktal digunakan karena konfigurasi fraktal pada rentang dimensi tertentu dapat menurunkan tingkat stress manusia. Maka 
eksplorasi yang menjadi tujuan dalam desain ini adalah menurunkan tingkat stress manusia baik di dalam maupun di luar bangunan. Eksplorasi arsitektur yang dilakukan pada proses desain mempunyai fokus pada pengalaman visual. Oleh karena itu, isu desain utama yang dibahas mengenai sirkulasi, image, dan legibilitas.

\section{METODA PERANCANGAN}

Pada proses desain apartemen ini, terdapat metode-metode yang digunakan untuk dapat menerapkan konfigurasi fraktal pada Apartemen, diantaranya:

\section{A. Identifikasi Parameter}

Mengidentifikasi parameter merupakan langkah pertama yang dilakukan untuk membuat batasan dalam desain agar kriteria yang diharapkan dapat tercapai. Dalam hal ini, parameter digunakan untuk menentukan wilayah rancangan dan mempengaruhi formal tools apa yang digunakan dalam proses desain. Parameter ini muncul karena kebutuhan untuk dapat memenuhi tujuan desain, yakni menurunkan tingkat stress manusia. Sehingga, parameter utama yang digunakan adalah Natural forces, kemampuan mata, dan dimensi fraktal.

Sebagai mana desain pada umumnya, Natural Forces pada konteks lahan itu sendiri merupakan parameter yang harus dipenuhi yaitu respon terhadap iklim dan perilaku sesuai konteks. Parameter ini tidak menjadi prioritas utama dalam mendesain karena parameter ini bukanlah fokus utama yang ingin dieksplorasi dalam desain. Parameter ini berpengaruh pada pembentukkan gubahan dan tatanan desain, yaitu bagaimana bentuk dibuat untuk memperoleh naung, bagaimana program ruang disusun, dll (Gambar 4).

Pengalaman visual yang dieksplorasi pada desain membuat kemampuan mata dalam menangkap sebuah objek untuk dapat diteruskan ke otak menjadi parameter yang menjadi prioritas. Parameter yang dibahas mengenai kemampuan mata ini adalah sudut mata, jarak mata memandang, juga kontras warna yang dapat diterima mata sehingga esensi fraktal dapat diterima otak dengan baik. Parameter sudut mata dari setiap titik potensial yang diproyeksikan ke arah area rancangan berpengaruh dalam penentuan besar wilayah desain (Gambar 5).

Dimensi fraktal sebagai parameter terakhir digunakan untuk batasan olahan wilayah desain yang sudah dioptimasi. Rentang dimensi fraktal menjadi kriteria yang harus dicapai pada desain ada pada 1.3 sampai 1.5. Dimana di luar rentang dimensi tersebut tidak berpengaruh apa-apa atau dapat menaikkan tingkat stress manusia [2].

\section{B. Superposisi}

Metode superposisi digunakan untuk menentukan sebuah posisi terbaik dari satu macam parameter yang memiliki banyak irisan sehingga wilayah dominan yang dipilih untuk dijadikan posisi yang paling pas untuk fungsi tertentu yang berkaitan dengan parameter tersebut [3]. Superposisi pada proses desain ini digunakan untuk mendapatkan wilayah rancang yang difungsikan untuk mendapatkan esensi fraktal dari luar maupun di dalam bangunan (Gambar 4). Dimana hal tersebut berpengaruh terhadap wilayah dan besar area yang akan difraktalkan.

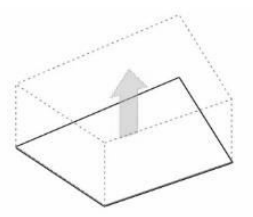

PUL
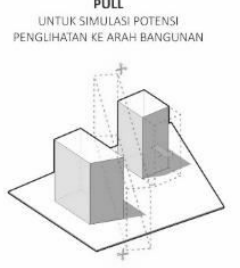

CUT AND PULL

DORCES ORLENTASI DARI TTTKK F
DAN PROGRAM RUANG.

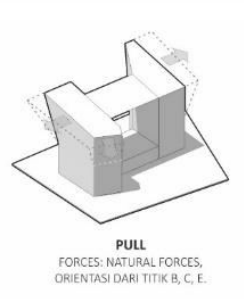

ORRENTASI DARI ITITKB, C, E,
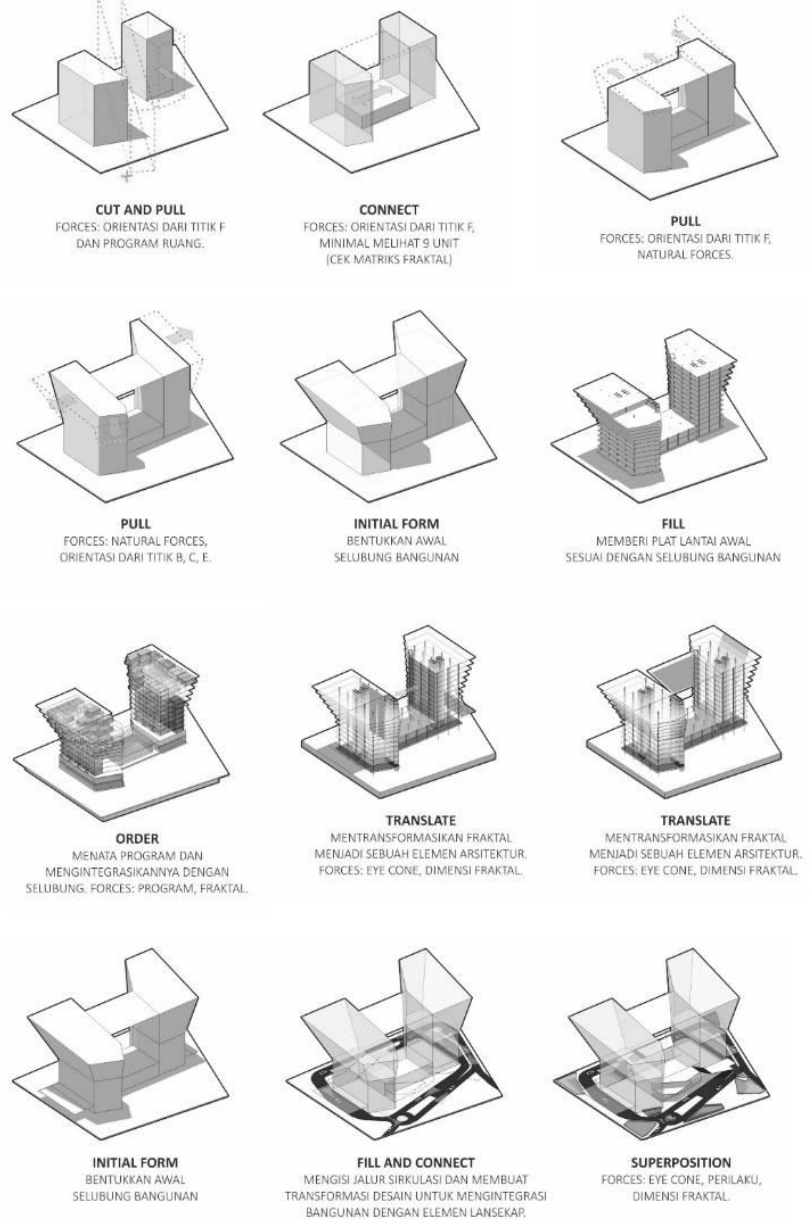
PULL
DRRES: ORIENTAS DARI TTIKF

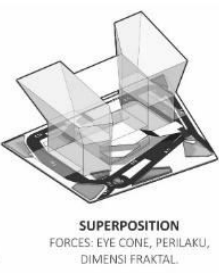

Gambar. 4. Sudut mata dari setiap titik potensial diproyeksikan ke arah lahan

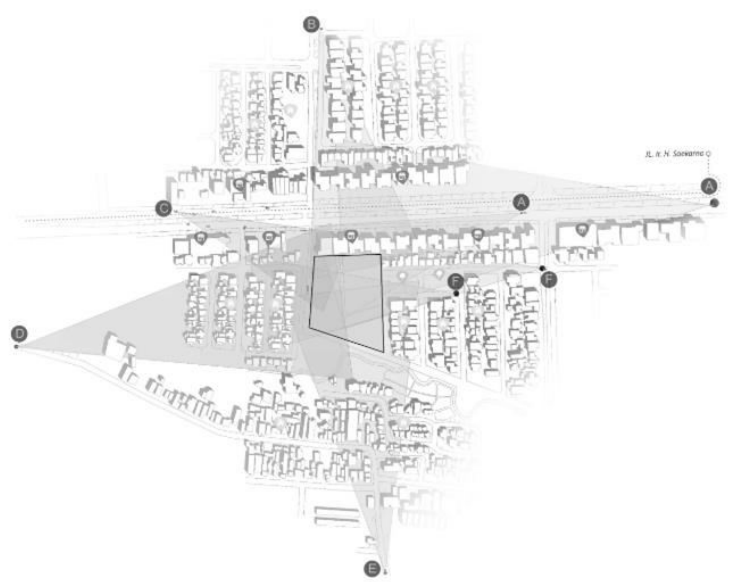

Gambar. 5. Diagram proses desain secara umum (belum termasuk detail pengolahan setiap sisi). 


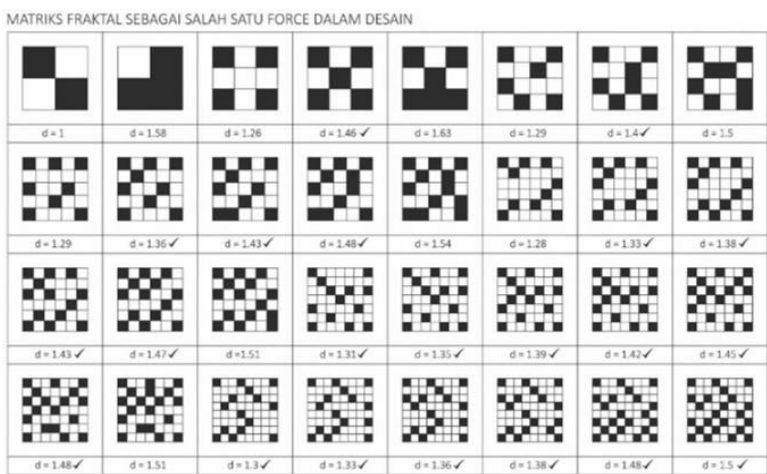

Gambar. 6. Studi konfigurasi fraktal untuk diterapkan pada sisi-sisi yang telah ditentukan. Rumus fraktal digunakan untuk dapat mengetahui dimensi fraktal sehingga keberhasilan desain dapat terukur.

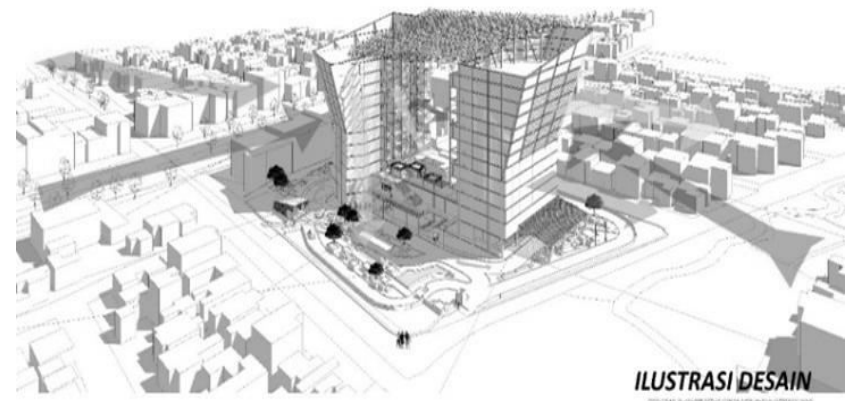

Gambar. 7. Diagram ini menunjukkan wilayah mana saja yang dirancang akibat dari titik-titik potensial yang telah dioptimasi.

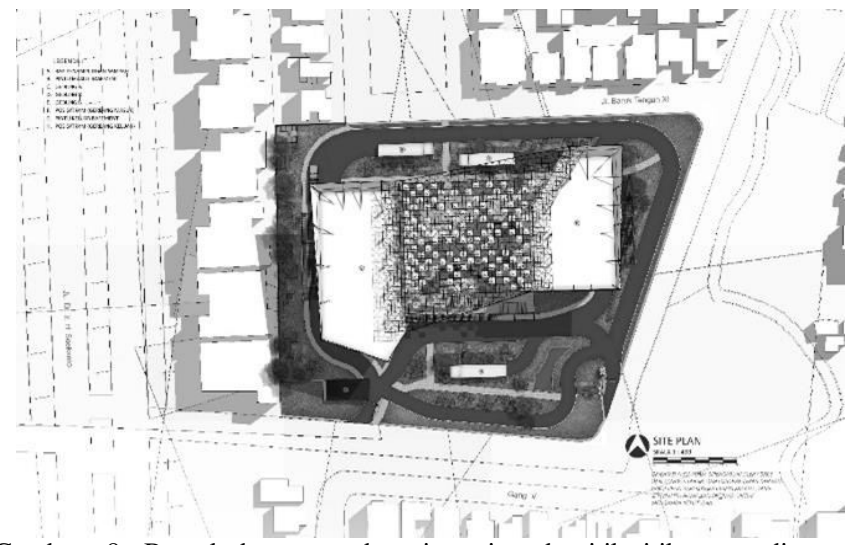

Gambar. 8. Bentuk bangunan berorientasi pada titik-titik yang dianggap potensial pada analisa lahan.

\section{Rumus Fraktal}

Untuk mengukur dimensi fraktal yang sesuai dengan kriteria, penulis menggunakan rumus fraktal yang digunakan untuk menentukan pola-pola yang akan dibuat pada sisi yang telah ditentukan. Rumus yang digunakan untuk mengukur dimensi fraktal adalah $\mathrm{D}=-\Delta \ln (\mathrm{Ni}) / \Delta \ln (\mathrm{xi})$ [2]. Rumus ini digunakan untuk mengetahui apakah pola yang didesain masih berada pada rentang dimensi fraktal yang ditetapkan (Gambar $6)$.

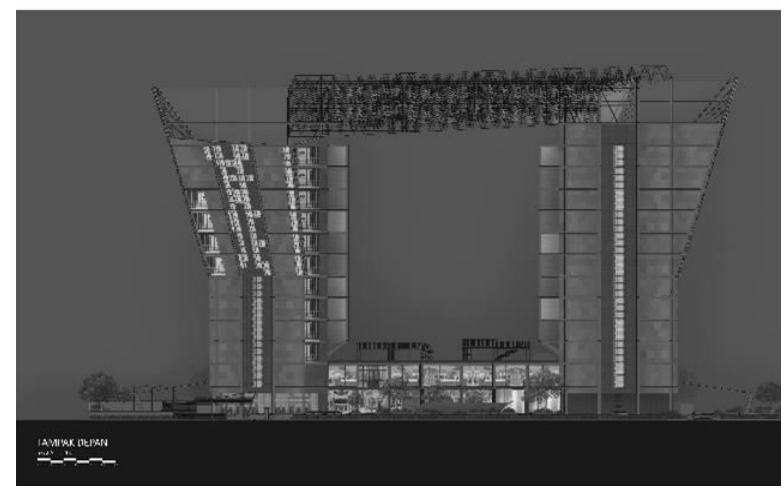

Gambar. 9. Pengolahan material dan cahaya pada tampak untuk dapat merespon waktu siang dan malam.

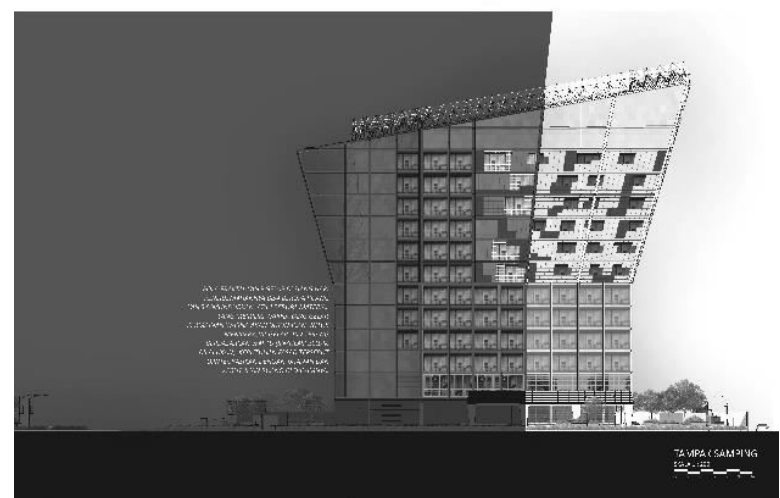

Gambar. 10. Pengolahan material dan cahaya pada tampak untuk dapat merespon waktu siang dan malam.

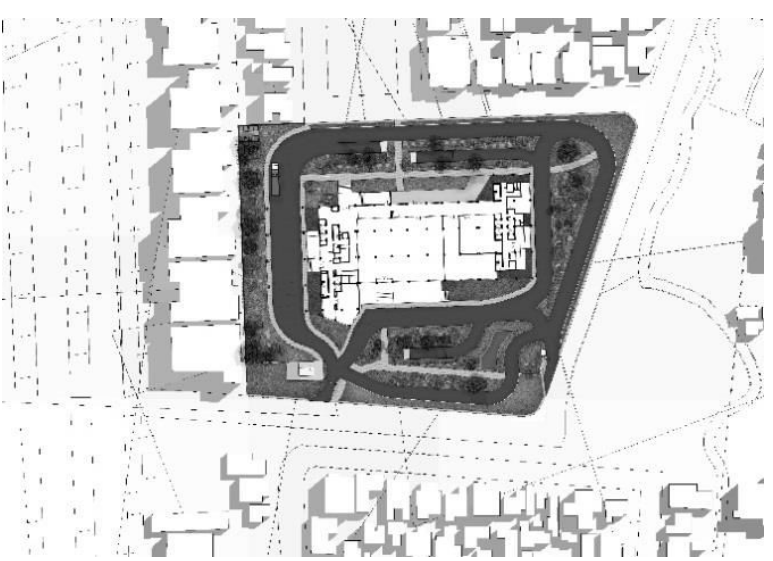

Gambar. 11. Hasil pengolahan elemen lasekap berdasarkan analisa titik potensial dan proyeksi sudut mata.

\section{HASIL DAN EKSPLORASI}

Pola fraktal pada arsitektur apartemen dapat dinikmati oleh manusia baik dari dalam maupun luar bangunan. penerapan pola fraktal dilakukan pada sisi-sisi yang berpotensi untuk dilihat. Dimana potensi tersebut ditentukan berdasarkan parameter-parameter yang sudah dijelaskan sebelumnya. Sehingga terbentuklah desain dengan olahan pola fraktal pada sisi-sisinya sesuai dengan respon terhadap titik-titik potensial tertentu (Gambar 7). Sehingga tujuan untuk menurunkan tingkat stress manusia dapat tercapai. Di bawah ini merupakan penjelasan dari setiap olahan-olahan tersebut: 


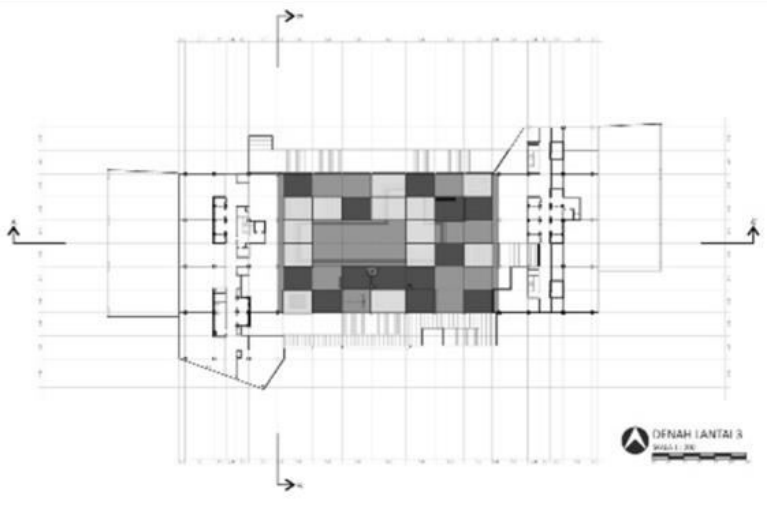

Gambar. 12. Hasil pengolahan material dan cahaya pada halaman terbuka di lantai tiga untuk dapat dinikmati dari balkon-balkon apartemen yang saling berhadapan.

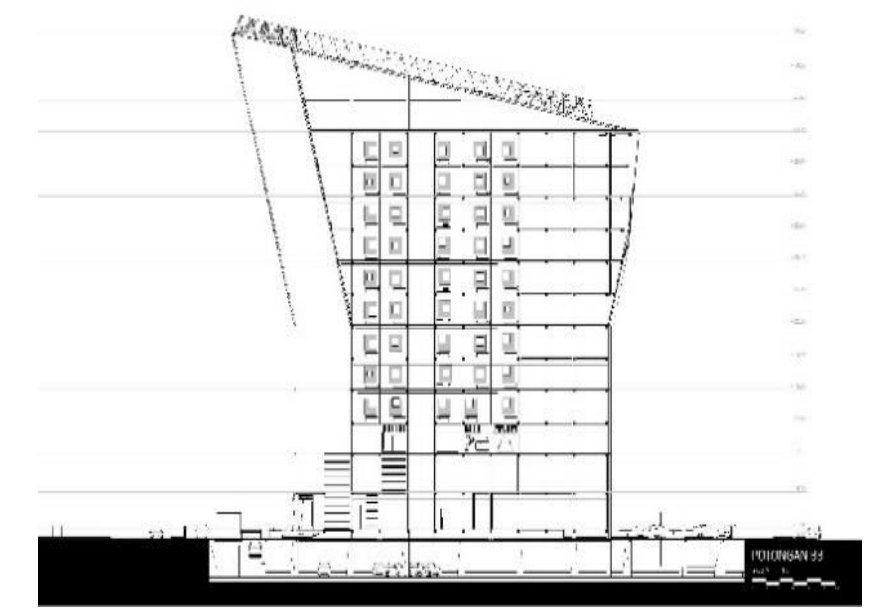

Gambar. 13. Setiap kamar memiliki bentuk dan ukuran jendela yang beragam untuk dapat memenuhi esensi fraktal saat melihat keluar jendela.

\section{A. Eksterior}

Pengolahan pola fraktal di sisi luar bangunan harus memperhatikan siang dan malam, karena hal tersebut berpengaruh terhadap persepsi otak untuk menangkap konfigurasi fraktal. Hal ini menjadi konsentrasi penulis karena perbedaan waktu mempengaruhi latar dari wilayah desain. Oleh sebab itu, pengolahannya harus bisa terintegrasi antara respon siang dan malam. Dimana pada desain direspon dengan penggunaan material dan cahaya untuk mendefinisikan warna gelap terang di waktu yang berbeda.

Wilayah-wilayah yang sisinya diberi olahan fraktal sebenarnya hanya berada pada sisi-sisi yang berada di luar saja. Namun, pengolahan pada sisi-sisi tersebut tetap ditujukan untuk penghuni maupun manusia yang sedang berada di luar. Olahan pada atap merupakan salah satu sisi yang dimaksud (Gambar 8). Sisi tersebut ditujukan untuk merespon titik-titik potensial yang berada di sebelah barat. Olahannya berupa penyusunan kain-kain tenda penutup dengan penggunaan warna yang gelap untuk respon pada waktu siang dan penggunaan lampu untuk respon pada waktu malam.

Olahan lainnya nampak pada sisi-sisi dinding yang menghadap langsung ke arah luar (Gambar 9 dan 10). Penggunaan material, warna, balkon, dan cahaya merupakan unsur yang diolah dalam desain. Penggunaan tekstur

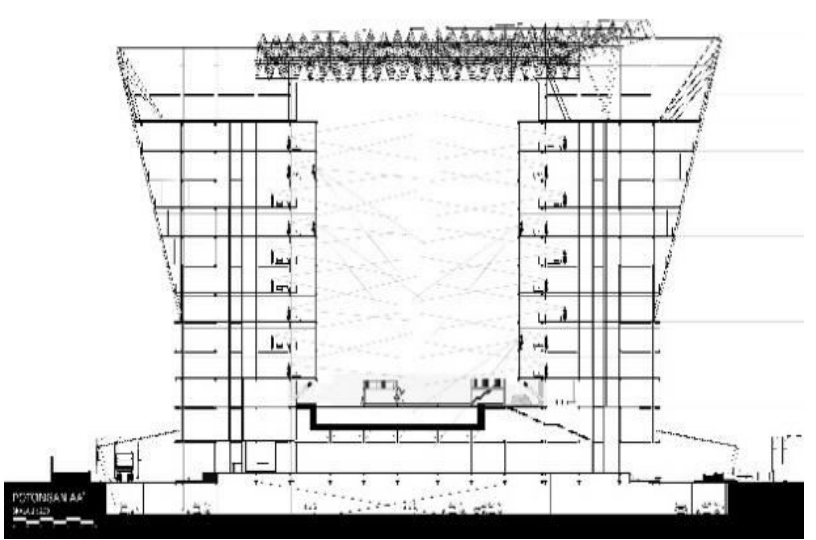

Gambar. 14. Unit apartemen yang berada di tengan(saling berhadapan) menjadi fokus penerapan pola fraktal. Unit tersebut dapat menikmati fraktal dengan melihat unit di seberangnya dan halaman terbuka di lantai tiga.

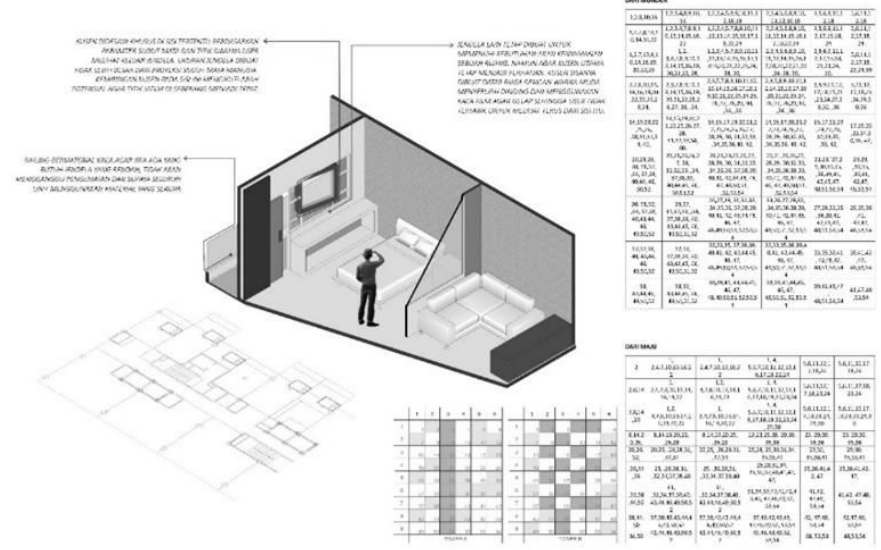

Gambar. 15. Ilustrasi pengolahan jendela kamar unit yang bersebrangan, juga ilustrasi bagaimana unit kamar yang maju dan mundur diletakkan.

material dan pembayangan merupakan respon desain untuk waktu siang. Sedangkan penggunaan lampu yang membuat area pada blok-blok tertentu menjadi terang merupakan respon desain untuk waktu malam.

Model aplikasi dari pola fraktal yang berbeda dapat dilihat dari penataan lansekapnya, baik pada ruang luar maupun pada halaman terbuka yang berada di lantai tiga. Sirkulasi pada ruang luar menentukan wilayah rancang yang potensial. Pada ruang luar, unsur yang dimainkan ada pada softscape dan hardscape (Gambar 11). Dimana pada olahannya membentuk konfigurasi gelap terang yang berbeda-beda. Berbeda dengan halaman terbuka di lantai tiga yang hanya bermain dengan unsur hardscape untuk membuat konfigurasi fraktal (Gambar 12). Sisi ini dipilih untuk dapat dilihat dari kamar-kamar apartemen yang saling berhadapan dan tidak mendapat view ke arah luar. Penerapannya pun tetap merespon untuk waktu siang dan malam dengan menggunakan permainan material, warna, dan cahaya.

\section{B. Interior}

Kamar-kamar apartemen yang tidak mendapat view ke arah luar menjadi perhatian dalam desain untuk diolah lebih agar dapat menurunkan tingkat stress penghuninya. Caranya yaitu dengan melihat ke arah kamar diseberangnya yang menerapkan pola fraktal dengan olahan bentuk, warna, dan 
cahya. Olahan tersebut ada pada jendela unik yang memiliki ukuran dan bentuk yang sedikit berbeda di setiap sisi ruangan (Gambar 13). Hal tersebut ditujukan agar penghuni yang berada di luar bangunan dapat melihat keluar melalui jendela masing-masing sesuai dengan parameter dimensi fraktal yang ingin dicapai (Gambar 14). Oleh sebab itu, pengolahannya jendela menjadi unik dan membutuhkan material dan arah hadap yang berbeda-beda untuk dapat menarik fokus penghuni pada jendela tertentu (gambar 15).

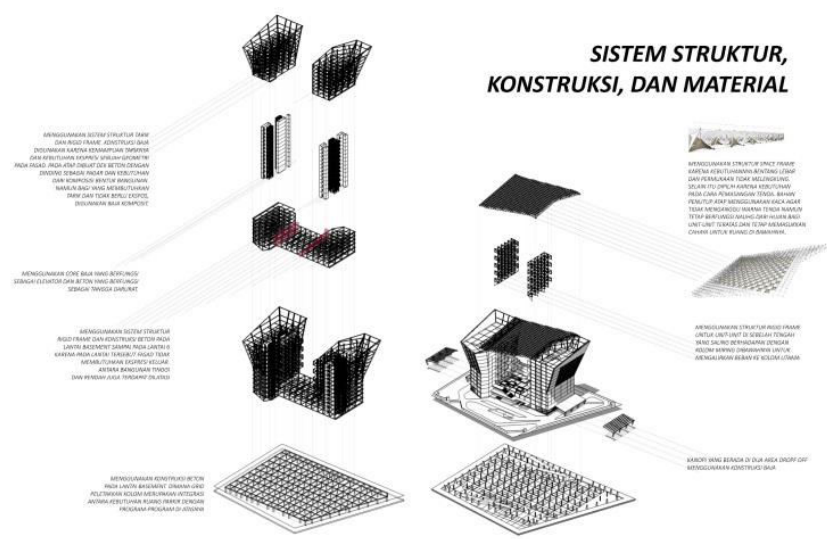

Gambar. 16. Ilustrasi penggunaan struktur penunjang konsep dan performa arsitektur apartemen.

\section{Sistem pendukung}

Layaknya bangunan pada umumnya, apartemen ini juga memiliki sistem pendukung untuk dapat memenuhi konsep dan performa desain (Gambar 16). Sistem-sistem yang dimkasud adalah sistem struktur, utilitas, dan arsitektur itu sendiri. Struktur tidak hanya ditujukan untuk firmitas, tetapi juga berperan bagi ekspresi bangunan. Oleh sebab itu desain ini menggunakan konstruksi baja untuk sisi-sisi terluar karena bangunan ini membutuhkan ekspresi yang ekspresif untuk membuat manusia yang berada di luar bangunan tertarik untuk melihat sekilas sehingga tujuan dapat tercapai.

Sistem utilitas dan arsitektur yang mendukung konsep utama dalam desain menjadi perhatian penting agar tujuan dapat tercapai. Pemilihan dan peletakkan material, warna, dan lampu menjadi penting karena mendefinisikan pola fraktal sesuai dengan rentang dimensi yang diharapkan. Diantaranya pun harus mampu terintegrasi agar dengan baik agar dalam satu sisi yang sama dapat mempunyai dua macam pola yang berbeda untuk dilihat di siang dan malam hari.

\section{KESIMPULAN}

Untuk menurunkan stress dengan cara desain yang dapat menerapkan pola fraktal, eksplorasinya akan berbeda-beda pada konteks lahan yang berbeda. Dalam desain ini, bentuk vertikal yang memiliki patahan dan membersar ke atas dapat memberi ekspresi dan diferensiasi pada setiap sisinya. Sehingga manusia tertarik untuk melihat dan dapat berinteraksi secara langsung secara visual dengan arsitektur apartemen ini. Olahan fraktal pada sisi-sisi yang ditetapkan dengan batasan dimensi 1.3-1.5 dapat dinikmati oleh penghuni maupun manusia yang berada di luar bangunan. Dengan begitu, apartemen ini dapat menjawab kebutuhan dari lahan untuk berperan dalam menenangkan psikologis manusia.

\section{DAFTAR PUSTAKA}

Febrianan and S. K. Tri, "Faktor-Faktor yang Mempengaruhi Stres Kerja," J. Ecopsy, vol. 1, no. 1, 2013.

[2] Salingaros and N. A., "Fractal Art and Architecture Reduce Physiological Stress," J. Biourbanism, 2012.

[3] P. Eisenman, Diagram Diaries. New York: Universe, 1999. 